\title{
Powerful qualities, the conceivability argument and the nature of the physical
}

\author{
Henry Taylor ${ }^{1}$
}

Published online: 15 September 2016

(C) The Author(s) 2016. This article is published with open access at Springerlink.com

\begin{abstract}
David Chalmers' 'conceivability' argument against physicalism is perhaps the most widely discussed and controversial argument in contemporary philosophy of mind. Recently, several thinkers have suggested a novel response to this argument, which employs the 'powerful qualities' ontology of properties. In this paper, I argue that this response fails because it presupposes an implausible account of the physical/phenomenal distinction. In the course of establishing this, I discuss the so-called 'ultimate' argument for the claim that dispositional properties form the subject matter of physics. I argue that the ultimate argument can be interpreted in a strong or a weak way, and that the strong interpretation is implausible. I argue that this undermines the powerful qualities based response to the conceivability argument. I also argue for a general conclusion: that we should not define 'the physical' exclusively in terms of a distinction drawn from ontology.
\end{abstract}

Keywords Powerful qualities · Physical - Dispositional properties · Conceivability argument · Ultimate argument · Chalmers

\section{Introduction: the conceivability argument and the powerful qualities view}

The conceivability argument represents the most prominent attack on physicalism in contemporary philosophy. A particularly unique response to the argument draws upon the 'powerful qualities' ontology of properties. Heil (2003) and Carruth (2016)

Henry Taylor

jht30@cam.ac.uk

1 Department of Philosophy, University of Cambridge, Sidgwick Avenue, Cambridge CB3 9DA, UK 
have argued that if one accepts the powerful qualities view, then Chalmers' conceivability argument fails.

This powerful qualities based response is worthy of careful consideration, for the following reasons: few arguments in recent philosophy have attracted as much attention as the conceivability argument, and employing the powerful qualities view to rebut it is an innovative option. The response is also particularly uncompromising in that it attacks the very first premise of the argument: that zombies are even conceivable. If the response is successful, then physicalists who are frustrated with other approaches to the conceivability argument will doubtless be interested in adopting the powerful qualities view. Thus, this argument has repercussions beyond philosophy of mind and into ontology more generally. The intersection of ontology and philosophy of mind is currently a very active and lively area of research (e.g. Soteriou 2013), and the powerful qualities response is an important part of this movement. Additionally, as we shall see in this paper, the powerful qualities response touches on questions of what ontological commitments we should draw from physics and how we should define 'physical'. Issues such as this are major sources of interest throughout metaphysics and philosophy of science.

In the present section, I outline the conceivability argument and the powerful qualities view. Then, I explain the powerful qualities based response to the conceivability argument (Sect. 2). In Sect. 3, I argue that the response assumes that the physical should be identified with the dispositional, which is implausible for independent reasons. Section 4 will examine the motivations in favour of identifying the physical with the dispositional, which mainly come from 'the ultimate argument' for the claim that dispositional properties form the subject matter of physics. I argue that there are strong and weak versions of this argument, and that the powerful qualities response relies on the strong version, which is implausible. In Sect. 5, I complete my defence of the conceivability argument. In Sect. 6, I draw general conclusions about how we should define 'physical' and 'phenomenal'. I argue that we should not define these in terms of already extant distinctions from metaphysics, but should adopt more neutral and less ontologically committal definitions.

\subsection{The conceivability argument}

Crucial to the conceivability argument is the notion of a zombie, which is a being physically identical to a conscious creature in every way (including brain structure, physical behaviour, etc.) but which lacks phenomenal consciousness. With this idea in mind, the argument proceeds as follows (for full details see Chalmers 2010, Chap. 6):

P1: Zombies are conceivable.

P2: If zombies are conceivable, then they are possible.

P3: If zombies are possible, then physicalism is false.

Conclusion: Physicalism is false.

Some distinctions will be important for the present discussion: Chalmers distinguishes between positive and negative conceivability. Something is negatively 
conceivable if it does not entail a contradiction, whilst positive conceivability involves picturing a scenario using 'modal imagination' (Chalmers 2002, p. 151). Chalmers believes the argument is sound when 'conceivable' is read in either way (2010, p. 148) but he thinks that positive conceivability is in a slightly better position to be a guide' to possibility (2002, p. 161). Additionally, Chalmers draws a distinction between prima facie conceivability (conceivability without much rational reflection) and 'ideal' conceivability (conceivability under 'ideal rational reflection'). It is the latter kind that is operative in P1 (Chalmers 2002, p. 148).

P2 has generated a huge amount of controversy (e.g. Papineau 2002). The justification for it relies on Chalmers' two-dimensional modal semantics as well as other distinctions between 'primary' and 'secondary' conceivability, and '1possibility' and '2-possibility' (Chalmers 2002, 2010, Chap. 6). However, the arguments that this paper is concerned with primarily attack P1, and can be understood without delving into these modal complications so I will set them aside here. I also do not discuss P3, and I assume the argument's validity.

\subsection{Powerful qualities}

Some claim that properties are essentially and exhaustively dispositional (or 'powerful'). On this view, there is nothing more to the nature of a property than the dispositions (or 'powers') that it imbues its bearer with to bring about particular manifestations when in the presence of certain stimuli (or 'partners') (Mumford 2004; Bird 2007a). On other views of properties, they are essentially 'categorical' or 'qualitative' and not essentially dispositional (Armstrong 1997; Lewis 2001). The powerful qualities view rejects these positions, and claims that all properties contribute both to the dispositional powers of the objects that instantiate them, and their qualitative (or 'occurrent' or 'categorical') nature. On the powerful qualities view, to describe any property in purely dispositional or purely qualitative terms is to give it an inadequate and inexhaustive description, because properties are all essentially both. Proponents of the view include Martin (1996, 2008), Strawson (2008), Jacobs (2011), Taylor (2013) and Heil (2003, 2005, 2012). ${ }^{1}$

The most prominent version of the powerful qualities view claims an identity: each dispositional property is identical with a qualitative property and vice versa. Heil says:

If $\mathrm{P}$ is an intrinsic property of a concrete object, $\mathrm{P}$ is simultaneously dispositional and qualitative; P's dispositionality and qualitativity are not aspects or properties of $\mathrm{P}$; P's dispositionality, $\mathrm{P}_{\mathrm{d}}$, is $\mathrm{P}$ 's qualitativity, $\mathrm{P}_{\mathrm{q}}$, and each of these is $P: P_{d}=P_{q}=P(2003$, p. 111).

This identity claim has consequences for the metaphysics of property instantiation that are vital for the argument I am considering. Specifically, it entails that any two objects that are alike in all of their dispositional properties must also be alike in

\footnotetext{
1 The powerful qualities view must be distinguished from the 'mixed' view (Molnar 2003) on which some properties are purely qualitative, and some are purely dispositional.
} 
all of their qualitative properties. The powerful qualities response to the conceivability argument assumes that the powerful qualities view is true, so I shall not debate the truth of the view here (see the works referenced above for arguments in favour of it). Additionally, all of the thinkers that I am concerned with accept the identity version of the view, so I shall accept it also.

\section{The powerful qualities response}

Heil and Carruth both give similar powerful qualities based responses to the conceivability argument, but Carruth's is more detailed, so I consider that first. Carruth claims that if we accept the powerful qualities view, we will uncover a contradiction in the notion of a zombie, and we can thus conclude that they are not negatively conceivable (2016, p. 32). This may seem odd because (as I pointed out above) Chalmers puts more weight on positive conceivability when putting forward the conceivability argument. However, this is not a problem for the following reason: Chalmers claims that for a situation to be ideally positively conceivable or ideally negatively conceivable, the situation must not be contradictory (2002, p. 153). For this reason, if the powerful qualities response successfully shows that the notion of a zombie is contradictory, then $\mathrm{P} 1$ of the argument can be rejected under either interpretation.

The powerful qualities response starts by trying to get a grasp on what is meant by 'physical'. Carruth quotes Chalmers, who emphasises that what is 'physical' comes down to the 'structure and dynamics' of systems (Chalmers 1996, p. 118. Quoted by Carruth 2016, p. 30). Carruth then claims that '[s]tructural and dynamic properties, at first glance, seem like ideal candidates for characterisation in purely dispositional terms' (2016, p. 34). For this reason, Carrruth takes 'physical properties' to mean 'dispositional properties' (Carruth 2016, p. 34). This is contrasted with phenomenal properties, which Carruth claims 'seem like ideal candidates for characterization in purely qualitative terms' $(2016$, p. 34). So, the powerful qualities response takes 'physical properties' to mean 'dispositional properties' and phenomenal properties to be a subset of the qualitative properties.

Importantly, proponents of the response are not claiming that physical properties are purely dispositional, or that phenomenal properties are purely qualitative (that would contradict the powerful qualities view). The claim is that physical properties are (by definition) to be equated with dispositional properties, and that phenomenal properties are qualitative, but this is consistent with the claim that both physical properties and phenomenal ones are powerful qualities, because powerful qualities are both dispositional and qualitative.

The response then continues: since a zombie is a physical duplicate of a normal person, but lacking in phenomenal experience, this means that it is a duplicate in all of its dispositional properties (because the response assumes that physical properties are equivalent to dispositional properties) but it is lacking in some of its qualitative properties (because phenomenal properties are taken to be qualitative). Carruth says: 
P1 asserts the conceivability of a world which is an exact dispositional duplicate of our world, but which differs with regard to its qualitative nature (2016, p. 34, emphasis added).

The argument then concludes as follows: if we accept that a zombie is like a normal human in all dispositional properties, but differing in their qualitative properties, then this contradicts the powerful qualities view. This is because (on the powerful qualities view) it is metaphysically impossible for there to be a duplicate of a person that is alike in all the person's dispositional properties, but which differs in their qualitative properties. So, if we accept the powerful qualities view, we will uncover a contradiction in the very notion of a zombie. In this way (claim the response's proponents), we can reject the conceivability argument by embracing the powerful qualities view.

Here is Carruth's summary of the argument:

[Chalmers] holds that no contradiction can be derived from the claim that a world alike in all its dispositional features to our own (a physical duplicate of our world) could differ in at least some of its qualitative features (not a duplicate of our world in terms of the conscious experiences that occur there)... [this view] fails to respect the identity claim central to [the powerful qualities view] (2016, p. 36).

Heil makes a very similar argument, saying:

Qualities and [dispositions] cannot vary independently. The possibility of zombies depends on the denial of this thesis (2003, p. 248).

Heil does not make explicit whether he denies P1 or P2 of the argument [Carruth interprets him the latter way (2016, pp. 37-38)]. In any case, if Heil is to target the conceivability argument as Chalmers understands it then (like Carruth) Heil must equate the dispositional with the physical (otherwise his claim that qualities and dispositions cannot vary independently will carry no force against Chalmers). I will thus address Carruth and Heil together.

\section{Physical $=$ dispositional?}

Two claims lie at the heart of the powerful qualities response. One of them is that phenomenal properties are qualitative properties. This could of course be doubted (Bird 2007b, p. 518 doubts it), but because the powerful qualities view states that all properties are in some sense qualitative and since phenomenal properties have usually been seen as archetypal examples of qualitative properties (e.g. Tugby 2012, p. 8), then anyone who accepts the powerful qualities view (as we are assuming for the sake of argument) is likely to believe that phenomenal properties are qualitative. So I will accept this claim.

The other claim that the argument relies on is an identification of the dispositional with the physical: that the domains of the physical and the dispositional are coextensive by definition. It is this identification that is used to 
justify the inference from the claim that a zombie is an exact physical duplicate of a normal human to the claim that it must be an exact dispositional duplicate of a normal human. Only once that claim is established can it be said that zombies have all of the same dispositional properties as normal humans, but lack some qualitative properties (because phenomenal properties are qualitative ones). Only then can it be claimed that the view is incompatible with the powerful qualities view (because the view entails that no two objects can be dispositionally alike, but differ qualitively).

The proponents of the response do not consider any reasons against identifying the dispositional with the physical. In this section, I argue that we should not equate physical properties with dispositional properties. I provide two arguments for this: firstly, such an identification would be inappropriate for the mind-body debate, even independently of Chalmers' conceivability argument. Secondly, the powerful qualities view itself gives us good reason to think that this identification is inadequate.

Identifying the physical and the dispositional would stipulatively make any view on which mental properties are dispositional automatically physicalist by fiat, regardless of how strange these properties are, or how dissimilar they are to normal physical properties like spin and charge. This is clearly the wrong result, a dualist view that takes mental properties to be dispositional should at least be a possible view that someone could hold. Consider the following position: the mind is a bundle of properties, none of which are spatially extended and none of which are shared by any objects that are paradigmatically taken to be physical (such as sticks and stones). Suppose further that these properties are not discussed in our best current physical theories, nor will they ever feature in any theory of physics (present or future) or any scientific theory at all. Furthermore, suppose that the bundle does not depend for its existence in any way (supervenience, identity, causation, grounding, realization, emergence...) on any objects (such as brains) that are studied by science. However, suppose that these properties are essentially dispositional: though they will never interact with what we consider normal matter, they are disposed to interact with each other in various ways, perhaps to produce thoughts or other mental states.

Such a view may be wrong. But regardless of this, we must surely deny that it is a physicalist view. However, if we simply equate 'the physical' with 'the dispositional' (as the powerful qualities response requires), then we are forced to admit that this view $i$ a physicalist view, because (in virtue of being dispositional) this bundle of properties must count as physical. But of course, saying that this is a physicalist view would run contrary to the way that the entire mind-body debate is carried out. Certainly, this is not the kind of view that Chalmers is attacking, nor is it a view that anyone calling herself a physicalist would countenance defending.

We need not have recourse to exotic examples in order to generate incorrect results. On some views, the self is a metaphysically simple emergent substance that has dispositional causal properties, irreducible and ontologically distinct from the causal properties of the brain (Lowe 2008, 2013). Such a view is normally (rightfully) taken to be a dualist view of both the self and of mental properties (Lowe certainly takes it this way). However, if we equate 'physical properties' with 
'dispositional properties', it follows that the dispositional causal properties of the emergent self must be physical properties. Again, this is the wrong result.

Am I simply engaging in a verbal dispute here over what 'physical' means? I think not. In the context of the mind-body debate, 'physical' is a theoretical term that has a certain role to play. In order to fulfil this role, it has to taxonomise the positions in a way that is reasonably faithful to how the interlocutors use the term 'physical', otherwise it fails to capture what the interlocutors in the debate are discussing, and it becomes useless as a theoretical term. The identification of the physical with the dispositional fails in just this way.

In addition to these worries, the powerful qualities view itself gives us excellent reason not to equate the physical with the dispositional, for the purposes of the conceivability argument. To see this, we can start with the claim that when we conceive of a physical duplicate of our world, we should use a concept of 'the physical' which 'specifi[es] the fundamental features of every fundamental microphysical entity' (Chalmers 2010, p. 142). Now, we may be sceptical of whether we are really capable of conceiving of all of these fundamental features, but it should be uncontroversial that we should conceive of such features as completely and accurately as we are able. ${ }^{2}$ Recall that the powerful qualities view is intended to apply to all properties, including fundamental microphysical properties such as mass and charge. Furthermore, on the powerful qualities view, to describe any property in purely dispositional terms is to give it an incomplete and inadequate description, because to exhaustively describe a property requires describing it in dispositional and qualitative terms. Thus, on the powerful qualities view, a dispositional account of normal physical properties such as mass and charge fails to specify the fundamental features of those fundamental properties. But this is what is required of the notion of 'the physical' in the conceivability argument.

So the powerful qualities view actually gives us reason to reject the notion of 'the physical' that equates it with the dispositional, because if you accept the powerful qualities view, then you must accept that a dispositional characterisation of the physical would fail to do adequate justice to the nature of physical entities. Indeed, one of the main reasons to be attracted to the powerful qualities view comes from dissatisfaction with a purely dispositional characterisation of normal physical entities. Heil himself criticises purely dispositional conceptions of physical matter, saying '[s]trip away the qualities, and it is no longer clear what, if anything, you are talking about' (2012, p. 71). And insists that a dispositional characterisation of physical matter would not give us 'a complete picture' (2012, p. 71. See also Strawson 2008, p. 278; Martin 2008, p. 63).

To sum up: the first issue is that identifying the dispositional with the physical would be theoretically useless in the mind-body debate, the second is that the powerful qualities view itself gives us reason to think that a dispositional conception of physical matter is inadequate, and this makes it unsuitable for use in the conceivability argument.

\footnotetext{
${ }^{2}$ Carruth accepts this claim (2016, p. 30).
} 


\section{The dispositional and the physical}

I have presented reasons to reject the identification of the physical with the dispositional. In this section, I will consider what reasons there might be in favour of this identification. In Sect. 4.1 I consider an argument that attempts to show that dispositional properties form the subject matter of physics. Section 4.2 I examine a weaker claim that is made by the adherents of the powerful qualities response: that Chalmers himself identifies the physical with the dispositional.

\subsection{The 'ultimate argument'}

A commonly invoked idea is that when physics interacts with the entities it studies, it necessarily does so in virtue of their dispositional properties, and it characterises them in dispositional terms. As Blackburn famously says: 'science finds only dispositional properties, all the way down' (1990, p. 63). Similarly, taking the example of negative charge, Hawthorne says:

[a]ll scientific knowledge about negative charge is knowledge about the causal role it plays. Science seems to offer no conception of negative charge as something over and above "the thing that plays the charge role" (2001, p. 368).

This claim forms the core of what has been called 'the ultimate argument'. The ultimate argument is often used to establish that science only gives us good reason to believe in purely dispositional properties, and so we should only accept such properties into our ontology (e.g. Mumford 2006; Molnar 2003, pp. 135-137). Those who defend the powerful qualities response to the conceivability argument do not employ the claim in that way, because they do not accept such views of properties. Rather, they use the core claim of the 'ultimate argument' (that physics characterises entities dispositionally) to support the identification of the physical with the dispositional (Carruth 2016, p. 34). The idea is something like this: physics is in the business of dispositional characterisations, so if we assume that we should tie our concept of 'the physical' to how physics characterises entities, then we should characterise the physical in terms of the dispositional. Like Carruth, Heil agrees with the claim at the centre of the ultimate argument, saying that dispositional characterisation 'lies at the heart of scientific theorizing' (2012, p. 71).

However, the central claim of the ultimate argument cannot be used to support the identification of the dispositional with the physical, as the powerful qualities response requires. We can see why by distinguishing between two claims:

(1) When physics studies an entity, it can only do so in virtue of that entity's dispositional properties and it can only characterise the entity in dispositional terms.

(2) Any entity with dispositional properties can be studied and characterised by physics.

\footnotetext{
3 The name 'ultimate argument' comes from Psillos (2006), though he has reservations about it.
} 
We can thus distinguish between a weak interpretation of the ultimate argument, which invokes (1), and a strong version, which invokes (1) and (2). (1) and (2) are not carefully distinguished in the literature, but they should be because they generate dramatically different views of the subject matter of physics. (1) is a claim about the limitations of physics. The considerations that I mentioned above about the methodology of physics lend support to (1). There is some plausibility to the claim that the only grasp science can get on the entities it studies is by way of their dispositional properties, thus there is some reason to accept (1), which is the weak version of the argument. By contrast, these considerations fall short of establishing (2). In order to establish (2), we would need an argument not just for the claim that physics can only study dispositional entities, but that it can study all dispositional entities. No argument given so far comes close to establishing that: they are all intended to show that physics is limited to describing only dispositional properties, not that all dispositional properties can be studied by physics. Indeed, there seems nothing incoherent about the idea (mentioned above) of a cluster of dispositional properties which do not interact in any way with normal matter (and which therefore cannot be studied by physics). So, we have no reason to accept the strong version of the argument. However, the powerful qualities response requires that all dispositional properties are physical (this is part of the identity claim between dispositional and physical properties) but without accepting (2), we have no good reason to make this claim.

Readers may wonder whether this claim (that all dispositional properties are physical) is strictly speaking required for the powerful qualities response to hold up. To see that it is, consider how the argument would work without it. Suppose we do not claim that all dispositional properties must be physical, and thus accept that the idea of a non-physical dispositional property is coherent. If this is coherent, then the inference from the claim that a normal person and a zombie are exactly alike physically to the claim that they are exactly alike dispositionally will no longer be justified, because it is coherent to suppose that they are alike physically but differ with relation to some non-physical dispositional properties. But if the zombie and the human can differ dispositionally, then the charge of incoherence that lies at the heart of the powerful qualities response collapses, because it only arises when we accept that the zombie and the human are entirely alike dispositionally but differ qualitively. So the argument fizzles out. An opponent could respond by insisting that non-physical dispositional properties are impossible, but obviously that would be to beg the question against any dualist who believes mental properties can be dispositional, and so this clearly cannot be assumed in the present context.

As another way of demonstrating the importance of the strong version of the ultimate argument, consider how the powerful qualities response would work if we only employed the weak version, if we only accepted (1). Even granting the argument's background assumptions, the most we could conclude from (1) is that all physical properties are dispositional properties. Then, since a zombie is a physical replica of a normal human, we can conclude that a zombie and a human must share at least some dispositional properties. However, we cannot conclude that they must be exactly alike dispositionally, because (again) they may differ in virtue of nonphysical dispositional properties. The idea of a non-physical dispositional property 
is entirely consistent with the claim that all physical properties are dispositional, and thus is consistent with the weak version of the argument. Again, the possibility of non-physical dispositional properties cannot be denied in this context, on pain of question begging.

Notice that we need not accept that there actually are any non-physical dispositional properties in order to stymie the powerful qualities response, we only have to accept the coherence of such properties in order to block the inference from the claim that zombies are physical duplicates of normal humans to the claim that they are dispositional duplicates. So, on any plausible interpretation of the ultimate argument, it is no help for the powerful qualities response.

\subsection{Chalmers}

Both Carruth and Heil give some dialectical reasons to identify the dispositional with the physical. Carruth claims that it is Chalmers' own preferred way of drawing the distinction (2016, p. 34). Heil does something similar, when he interprets Chalmers' notion of a zombie as being a functional duplicate of a normal human [Heil seems to equate the functional with the dispositional (2003, pp. 243-245)]. If this is true, then the powerful qualities theorists can claim a dialectical victory: the powerful qualities view defeats the conceivability argument if we adopt Chalmers' own definition of 'physical'. In this section, I argue that this is a misrepresentation: there is no good reason to think that Chalmers equates the physical with the dispositional.

As mentioned in Sect. 2, Carruth attributes to Chalmers the view that the physical should be understood in terms of the dispositional based on Chalmers' claim that physics is concerned with the 'structure and dynamics of physical processes' (1996, p. 118). Carruth then claims that '[s]tructural and dynamic properties, at first glance, seem like ideal candidates for characterisation in purely dispositional terms' (2016, p. 34). However, this is dubious. Firstly, it is controversial whether structural properties can be adequately characterised in dispositional terms. Some have claimed that they can (Martin 2008; Mellor 1974) whilst others have claimed that they are ideal candidates for purely qualitative (or categorical) description (e.g. Pereboom 2011, p. 91). Interestingly, some thinkers who have argued most strongly for an ontology of dispositions now accept that certain properties cannot be given adequate dispositional characterisations, because of their structural features. Alexander Bird gives the examples of being heterocyclic (having a carbon-containing ring) and being pericardial (surrounding the heart), saying '[s]cience is full of references to properties that are not at all dispositional' (2016, p. 355).

Secondly, Chalmers himself does not ally structure and dynamics with dispositional properties (2010, pp. 120-123). Rather, he contrasts structural and dynamic properties with 'intrinsic' properties of objects (e.g. 2010, p. 121) indicating that he takes structural and dynamic properties to be extrinsic properties. We may ask whether Chalmers is here using 'extrinsic' and 'intrinsic' in a specific way. For example, are properties such as mass extrinsic or intrinsic, in the sense relevant to the interpretation of structure and dynamics? These are complicated questions and are deeply tied up with Chalmers' advocacy of a Russellian monist metaphysics. On the Russellian 
monist picture, science cannot give an account of the 'intrinsic' nature of objects and properties. When Chalmers talks about 'structure and dynamics' he is contrasting them with properties that are intrinsic in this particular sense. So, whether properties such as 'charge' and 'mass' count as extrinsic or intrinsic properties in this sense depends on whether one takes those terms to refer only to the features of objects that science can give an account of (in which case they would not be intrinsic) or whether the terms also refer to an inner nature that cannot be studied by science (in which case they would be partially intrinsic). ${ }^{4}$ In any case, the way that Chalmers cashes out 'structure and dynamics' does not straightforwardly ally structural and dynamical properties with dispositional ones.

The same is true of the interpretation of 'structure and dynamics' that we get from Alter (2015) and Pereboom (2011), who have helpfully expanded on Chalmers' comments. They suggest that the more precise way to use the extrinsic/ intrinsic distinction to cash out 'structure and dynamics', for Chalmers' purposes, is to say that the structural and dynamical properties of some object are those properties that are either extrinsic to the object tout court, or are those properties of the object such that all of the truths about them are deducible from truths about the extrinsic properties of the object's parts. Again, this cashes out structure and dynamics in terms of the intrinsic/extrinsic distinction, rather than in terms of dispositions. ${ }^{5}$

Indeed, even if it were true that by 'structure and dynamics' Chalmers means 'dispositional', this need not lead us to identify the physical with the dispositional, because Chalmers does not think that all structure and dynamics is physical. Rather, he believes that conscious experiences have structural and dynamic properties, even though they are non-physical (2010, p. 122). Rather, the place of structure and dynamics in Chalmers' argument is to demonstrate the limitations of physics, rather than give a definition of 'the physical'. 6

The basis of Heil's argument is slightly different from Carruth's. He interprets the zombie world to be a functional duplicate of this one, and then equates the functional with the dispositional (2003, pp. 243-245). However, for the conceivability argument to stand up, Chalmers does not need to claim that the zombie world is a perfect functional/dispositional replica of our world, he need only claim that it is a physical replica of our world. Of course, a zombie world has all of the same functional/dispositional properties that logically supervene on physical properties in the actual world, but this does not imply that the zombie world must be a functional/ dispositional replica of our world, because the two worlds may differ in regard to

\footnotetext{
4 See Chalmers (2010, p. 134).

5 Alter (2015) considers various other ways of understanding 'structure and dynamics', none of which equate structure and dynamics with dispositional properties.

6 Carruth comments that Chalmers' 'hard problem' of consciousness (Chalmers 1995) trades off the intuition that phenomenal properties are intrinsic and qualitative features of experiences (Carruth 2016, p. 37 and p. 43). But at most, this shows that Chalmers should hold onto the claim that phenomenal experiences are intrinsic and qualitative: it does not entail that the physical must be equated with the dispositional.
} 
functional/dispositional properties that do not logically supervene on physical properties in the actual world.

\section{The conceivability argument saved}

Suppose we accept the powerful qualities view but reject the identification of the physical with the dispositional, as I have urged. Then to say a zombie is conceivable is to say that it is coherent that there could be a being that has all the same physical properties as a human, but lacks their phenomenal properties. Assuming that both phenomenal properties and physical ones are powerful qualities, then the zombie would differ both dispositionally and qualitively from the normal human. Since we have rejected the identification of the dispositional with the physical, this is perfectly coherent. So the conceivability argument is saved.

At one point, Carruth mentions a position similar to the one that I have just outlined, but rejects it mainly on the basis that it relies on:

giving up on the idea that the distinction between the physical and the mental is to be drawn in terms of dispositionality and qualitativity (2016, p. 43).

However, if what I have argued in this paper is correct, then this is no criticism of the position, because this way of drawing the distinction should be rejected, for independent reasons that neither Heil nor Carruth consider.

Carruth backs up his scepticism by pointing out another way in which the powerful qualities view may cause trouble for the conceivability argument, even if we do reject his preferred way of drawing the physical/phenomenal distinction. Carruth claims that if we accept that phenomenal properties and physical ones are both powerful qualities as well as accepting the possibility of zombies, then this implies that phenomenal properties are not produced by physical ones in the actual world (2016, pp. 43-44). The reasoning is as follows: the powerful qualities view involves commitment to a view of causal production as a manifestation of dispositional powers. So if phenomenal properties are produced by the manifestations of physical properties in the actual world, then they must also be produced wherever those physical properties are duplicated, such as the zombie world. But this contradicts one of the basic claims of the conceivability argument: that zombies do not have phenomenal properties. Therefore, the proponent of the conceivability argument must reject the claim that physical properties produce phenomenal properties in the actual world.

There are two possible responses to this. The first is to accept that the interaction of physical powerful qualities produces phenomenal properties in the actual world, but deny that they do so in the zombie world. This is a fruitful way for the dualist to go, though it hinges on denying that dispositional interactions metaphysically necessitate their effects. If the dualist feels that an argument in favour of this denial is required, then she may claim that in the zombie world there are 'interferers' or 'antidotes' which prevent the interaction of powerful qualities from producing phenomenal properties and that therefore the interaction of powerful qualities does 
not metaphysically necessitate phenomenal properties. ${ }^{7}$ Of course, these interferers could not be physical, because the zombie world would then not be a physical duplicate of our world, so they would have to be non-physical. Here the debate may become difficult to adjudicate dialectically, because the physicalist could claim that by assuming that such non-physical interferers exist in the zombie world, the dualist is begging the question. The dualist could then respond that this does not beg the question, because the physicalist only denies the existence of such non-physical entities in the actual world, so invoking non-physical interferers in another possible world is dialectically fine, and that surely the onus of proof is on the physicalist to show that non-physical interferers are metaphysically impossible.

The second response to this problem is dialectically clearer: the proponent of the conceivability argument could deny that the relationship between physical and phenomenal properties is a causal one, or at least claim that it is not one that functions by the manifestation of powerful qualities. Such a dualist could instead claim that the relationship is one of emergence, thus avoiding the issues connected to whether dispositional interactions metaphysically necessitate their effects.

Readers may think that there is also another way in which the powerful qualities view might be problematic for the conceivability argument. Suppose we accept the powerful qualities view, and thus accept that phenomenal properties are powerful qualities. Powerful qualities are essentially dispositional and dispositional properties have causal powers. So, the view is incompatible with epiphenomenalism. If this were so, this would be a problem because epiphenomenalist dualism is one of the positions that the conceivability argument has been used to support. However, epiphenomenalism only states that phenomenal properties do not have causal effects on the physical world, but it allows that phenomenal properties could have causal powers to interact with other (non-physical) mental properties (cf. Jackson 1982, p. 133). Furthermore, it is consistent with this view that phenomenal properties are powerful qualities that never actually exercise their causal powers at all. Powerful qualities (like all dispositional properties) can exist whether or not they ever actually engage in the interactions that they are disposed for (cf. Martin 1996, p. 74).

\section{Conclusion: How not to define 'physical' and 'phenomenal'}

There is a general lesson to be uncovered from the arguments of this paper, connected to how we set up the entire debate over physicalism. It is that we should not formulate our definitions of 'physical' and 'phenomenal' exclusively in terms of a distinction drawn from ontology. The reason for this is that the debate over the metaphysics of consciousness is a debate over the fundamental nature of consciousness, the nature of the physical world, and how the two fit together. If we define the physical/phenomenal distinction at the very outset of the debate in terms of an already extant distinction from ontology (such as the dispositional/

\footnotetext{
${ }^{7}$ See Bird (1998) and Mumford and Anjum (2011) for more on antidotes and interferers.
} 
qualitative distinction) then we are already assuming something about the fundamental metaphysical nature of phenomenal consciousness and of the physical world, and how they are related to one another. However, this is precisely what is at issue in the debates over the metaphysics of consciousness. For this reason, defining the physical/phenomenal in purely metaphysical terms is likely to beg important questions, which is precisely the kind of problem we have uncovered in this paper.

This kind of worry should lead us to seek accounts of 'physical' or 'phenomenal' that are less committal about what the ontological nature of the physical and the phenomenal, so that the debate over the metaphysics of consciousness can proceed against a neutral background. One candidate for such an approach is Alyssa Ney's (2008) proposal that we need not provide a neat definition of 'the physical' because physicalism should be seen more as an attitude that we take towards our ontology rather than a strict doctrine (we might add to this the constraint that fundamental physical properties cannot be mental, Wilson 2006). This approach avoids the assumption that the physical and the phenomenal must neatly fit into ontological categories that already exist and it allows a reasonable amount of metaphysical flexibility in what can and cannot count as physical. Of course, this is not to say that ontological notions have no place in our understanding of the physical, or physicalism more generally. It is simply to say that we should avoid defining the distinction purely in these terms, if we want to set up the debate in a fruitful way.

I will address one concern that was put to me about this approach. ${ }^{8}$ It may be wondered that if the concept 'physical' that we use is ontologically flexible, then we may not have enough of a grasp on what 'the physical' is to confidently endorse the claim that we can conceive of a physical duplicate of us. It may be worried that this undercuts the motivation for endorsing P1 of the conceivability argument. To see how this problem can be dealt with, consider Ney's suggestion, which I mentioned above. To Ney, the physicalist ontology includes whatever physics ranges over at the time, because (though physics may change in the future) it is the best guide to our ontology that we currently have available. On this view, we can derive our grasp of what is 'physical' from current physics, and run P1 of the conceivability argument using that understanding. Using this understanding, then if the conceivability argument succeeds, this will only allow us to make a provisional conclusion: that physicalism is not the best attitude for us to take at the moment, even if the argument will have to be reassessed in the light of future discoveries from physics. However, given how philosophically significant even the provisional conclusion is, it is still adequate to get the conceivability argument going.

In more general terms, it is entirely consistent with what I have argued that we could have an extensively fleshed out conception of 'the physical' to satisfy the requirements of conceivability that we find in P1. It is simply that these details cannot be based entirely on a distinction from metaphysics specifically. Once this proviso is met, the account can be as thorough as we like.

8 Thanks to an anonymous referee. 
Acknowledgments Thanks to Alexander Carruth and an anonymous referee for comments on an earlier draft. Thanks also to the Leverhulme Trust and the Isaac Newton Trust for an Early Career Fellowship (ECF-2015-088) that provided support while the paper was being written.

Open Access This article is distributed under the terms of the Creative Commons Attribution 4.0 International License (http://creativecommons.org/licenses/by/4.0/), which permits unrestricted use, distribution, and reproduction in any medium, provided you give appropriate credit to the original author(s) and the source, provide a link to the Creative Commons license, and indicate if changes were made.

\section{References}

Alter, T. (2015). The structure and dynamics argument against materialism. Noûs. doi:10.1111/nous. 12134.

Armstrong, D. (1997). A world of states of affairs. Cambridge: CUP.

Bird, A. (1998). Dispositions and antidotes. The Philosophical Quarterly, 191, 227-334.

Bird, A. (2007a). Nature's metaphysics. New York: OUP.

Bird, A. (2007b). The regress of pure powers. The Philosophical Quarterly, 57, 513-534.

Bird, A. (2016). Overpowering: How the powers ontology has overreached itself. Mind, 125, 341383.

Blackburn, S. (1990). Filling in space. Analysis, 50, 62-65.

Carruth, A. (2016). Powerful qualities, zombies and inconceivability. The Philosophical Quarterly, 66, 25-46.

Chalmers, D. (1995). Facing up to the problem of consciousness. Journal of Consciousness Studies, 2, 200-219.

Chalmers, D. (1996). The conscious mind. Oxford: OUP.

Chalmers, D. (2002). Does conceivability entail possibility? In T. Gendler \& J. Hawthorne (Eds.), Conceivability and possibility. Oxford: OUP.

Chalmers, D. (2010). The character of consciousness. Oxford: OUP.

Hawthore, J. (2001). Causal structuralism. Philosophical Perspectives, 15, 361-378.

Heil, J. (2003). From an ontological point of view. Oxford: OUP.

Heil, J. (2005). Dispositions. Synthese, 144, 343-356.

Heil, J. (2012). The universe as we find it. Oxford: OUP.

Jackson, F. (1982). Epiphenomenal qualia. The Philosophical Quarterly, 32, 127-136.

Jacobs, J. (2011). Powerful qualities, not pure powers. The Monist, 94, 81-102.

Lewis, D. (2001). Ramseyan humility. In D. Braddon Mitchell \& R. Nola (Eds.), The Canberra plan. Oxford: OUP.

Lowe, E. J. (2008). Personal agency. Oxford: OUP.

Lowe, E. J. (2013). Substance causation, powers and human agency. In S. C. Gibb, E. J. Lowe, \& R. D. Ingthorsson (Eds.), Mental causation and ontology. Oxford: OUP.

Martin, C. B. (1996). Properties and dispositions. In T. Crane (Ed.), Dispositions: A debate. New York: Routledge.

Martin, C. B. (2008). The mind in nature. New York: OUP.

Mellor, D. H. (1974). In defence of dispositions. The Philosophical Review, 83, 157-181.

Molnar, G. (2003). Powers. Oxford: OUP.

Mumford, S. (2004). Laws in nature. USA: Routledge.

Mumford, S. (2006). The ungrounded argument. Synthese, 149, 471-489.

Mumford, S., \& Anjum, R. (2011). Getting causes from powers. New York: OUP.

Ney, A. (2008). Physicalism as an attitude. Philosophical Studies, 138, 1-15.

Papineau, D. (2002). Thinking about consciousness. New York: OUP.

Pereboom, D. (2011). Consciousness and the prospects of physicalism. New York: OUP.

Psillos, S. (2006). What do powers do when they are not manifested? Philosophy and Phenomenological Research, 72, 137-156.

Soteriou, M. (2013). The mind's construction. Oxford: OUP. 
Strawson, G. (2008). The identity of the categorical and the dispositional. Analysis, 68, 271-282.

Taylor, J. (2013). In defence of powerful qualities. Metaphysica, 14, 93-107.

Tugby, M. (2012). Rescuing dispositionalism from the ultimate problem: Reply to Barker and Smart. Analysis, 72, 723-731.

Wilson, J. (2006). On characterising the physical. Philosophical Studies, 131, 61-99. 